\title{
An Analytical Study on Interactions of Artificial Cracks and Holes Contributing to Increases in the Shear Strengths of RC Beams
}

\author{
Yuta Yamada ${ }^{1 *}$
}

Received 5 June 2019, accepted 1 October 2019

doi:10.3151/jact.17.579

\begin{abstract}
This study investigated the effects of cracks along rebars in reinforced concrete (RC) beams with multiple holes inside the shear spans mainly based on nonlinear finite element (FE) analyses. The analytical parameters were the hole positions that increased the shear strengths of RC beams in static loading experiments, the crack positions, and the widths. As a result of the analyses, for beams with holes arranged from near the loading points toward the positions of tensile rebars at the mid-shear span with no stirrups, when the beams had a horizontal crack, the strengths increased to the flexural capacities. However, when the beam had vertical cracks, the strength decreased to $80 \%$ for beams without holes. Meanwhile, for beams with holes arranged from the bottom side of the loading points toward the mid-height with no stirrups, the strength increased to between $110 \%$ and $160 \%$ compared with beams without holes regardless of the crack positions. Moreover, the shear behaviors of the beams did not change when the equivalent crack width exceeded $0.3 \mathrm{~mm}$ for each case, and changes in the behaviors of beams with stirrups were negligibly small regardless of the hole positions. It was made clear that changes in the behaviors were caused by the contributions of arch mechanisms enhanced by localizations and expansions of the minimum principal stress distributions owing to the multiple holes.
\end{abstract}

\section{Introduction}

In general, repairing and reinforcing methods for reinforced concrete $(\mathrm{RC})$ structural members restore the apparent structural performance by resistance to external forces. However, there are difficulties in applying proposed repairing and reinforcing methods to all deteriorated infrastructures owing to restrictions of time and cost. A simplified restoring method for the structural performance is required to construct a more efficient maintenance strategy. Moreover, a method to restore the shear capacity is needed to prevent brittle failure.

There is a method in which artificial devices are introduced in RC members to restore the structural performance without using reinforcement materials. Previous studies proposed methods to strengthen the shear capacity by introducing artificial devices (Pimanmas and Maekawa 2001) or high-stiffness materials (Kobayashi and Sasaki 2014) inside the RC members by controlling the crack paths.

In a previous study regarding the fatigue behaviors of RC beams with artificial cracks (Yamada et al. 2016), it was found that when the artificial crack tips were inside the region where the vertical stress could be neglected, the shear capacity increased compared with beams without cracks as a result of higher stress concentrations at the crack tips. Thus, an increase in the shear capacity can be induced if stress fields can be changed by stress concentrations.

${ }^{1}$ Research Assistant, College of Science and Technology, Nihon University. *Corresponding author.

E-mail: yamada.y@civil.cst.nihon-u.ac.jp
If the stress fields can be changed by drilling holes using core drills (which has been widely used to take out cylinder test pieces from actual infrastructures), restoration of the structural performance can be even more simplified. The merits of using core drills are a reduction in temporal costs and ease of avoiding interlap between rebars and drilling positions because the diameters of the core drills can be changed for the spacing of reinforcement. These merits expand the range of applicability to constructed structural members.

According to a previous study that tried to increase the shear capacity by introducing a hole inside each shear span (Yamada 2018b), it was confirmed that the capacity decreased when the beam had a hole inside compressive-stress-predominant regions compared with beams without holes. In addition, the contribution of the beam mechanism increased when the beam had a hole near the supporting points. However, the effects of multiple holes have not been confirmed, and it can be expected that the shear capacities will increase if the load carrying mechanisms are changed by multiple holes. Furthermore, no study has clarified the interactions between cracks due to aging deterioration and the existence of the holes.

This study conducted nonlinear finite element (FE) analyses for beams with several types of multiple holes that strengthened the shear capacity in the static loading experiments that were conducted to obtain fundamental knowledge of the interactions. Vertical cracks that modeled the corrosion cracks along all stirrups and horizontal cracks that modeled the cracks along tensile rebars were examined, and the effect of the crack width was investigated. 


\section{Macroscopic behavior of beams with multiple holes}

\subsection{Experimental overview}

This chapter describes results and overview of static loading experiments to determine the macroscopic behaviors of beams that have multiple holes. The size and shape of the specimens are shown in Fig. 1. The experimental cases are listed in Table 1. The shear span ratio $a / d$ was set at 3.0 to clarify the behavior of slender beams. The beams were designed to fail in shear for sound states. $\mathrm{N}$ represents a beam without holes and stirrups. M1 represents a beam without stirrups and with holes arranged from the bottom side of the loading points toward the mid-height. M2 represents a beam without stirrups and with holes arranged from near the loading points toward positions of tensile rebars at the midshear span.

The holes were arranged on the spline curves in the case of M1 and M2. RN, which was tested in a previous study (Yamada 2018b), represents a beam with stirrups. Holes were introduced in the beams by embedding polyvinyl chloride circular pipes whose diameters were 22 $\mathrm{mm}$ at the time of specimen casting. The polyvinyl chloride pipes were arranged to penetrate perpendicular to the beam directions and were removed after concrete hardening. The main reinforcement ratio in all cases was $1.7 \%$, and the shear reinforcement ratio in the case of $\mathrm{RN}$ was $0.5 \%$. Static loading experiments were conducted in a four-point bending condition, and the loading speed was maintained at less than $1 \mathrm{kN} / \mathrm{s}$.

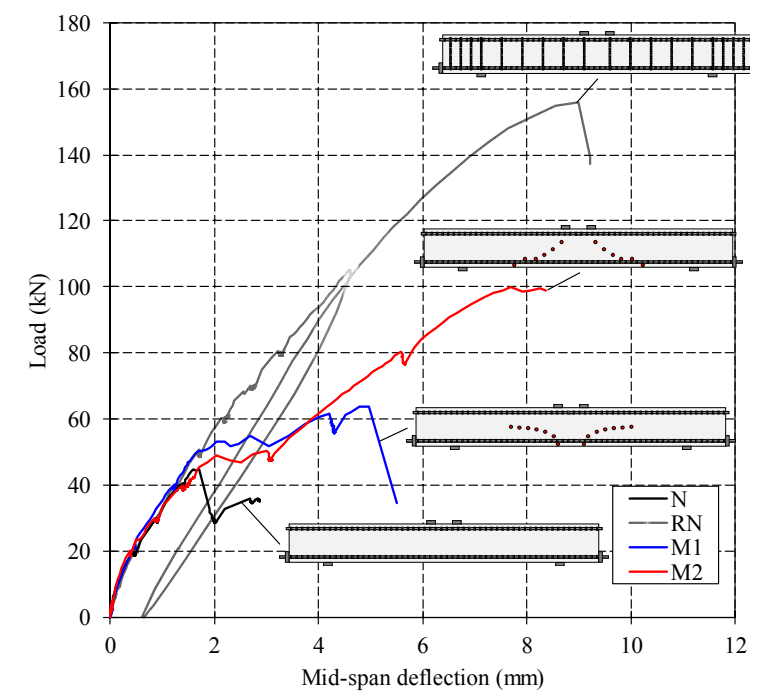

Fig. 2 Load deflection curves.

\subsection{Experimental results}

The load deflection curves are shown in Fig. 2, and crack distribution maps at failure are illustrated in Fig. 3. The loads in Fig. 2 represent twice the applied shear forces. In the case of $\mathrm{N}$, a diagonal crack occurred at around $40 \mathrm{kN}$; after that, it failed via diagonal cracking failure at 44.9 $\mathrm{kN}$ [Fig. 3(a)]. In the case of M1, the first diagonal crack occurred at around 40 to $50 \mathrm{kN}$, after which it failed by the occurrence of a diagonal crack formed outside the first diagonal crack at $63.8 \mathrm{kN}$ [Fig. 3(b)]. In the case of $\mathrm{M} 2$, a diagonal crack occurred at around 40 to $50 \mathrm{kN}$ and along the holes. After that, it failed in a bond-splitting failure at $99.8 \mathrm{kN}$ with propagations of horizontal cracks

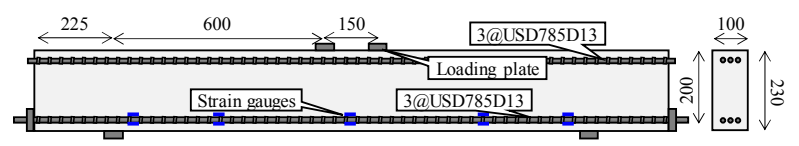

(a) $\mathrm{N}$

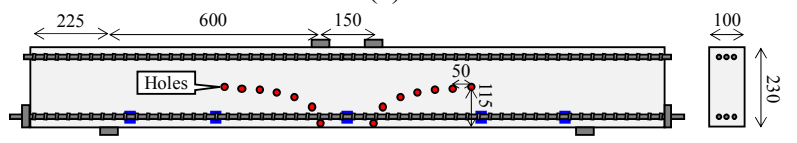

(b) M1

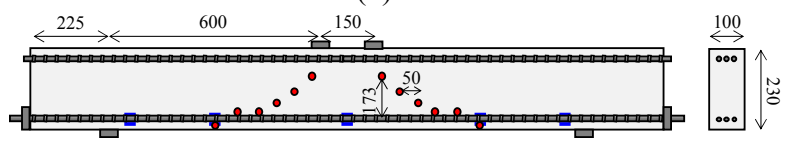

(c) M2

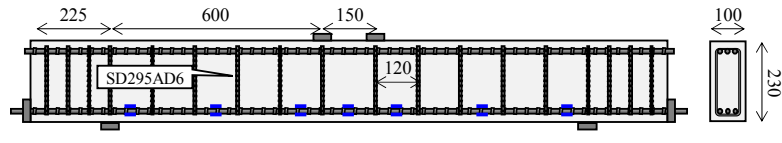

(d) $\mathrm{RN}$

Unit: $\mathrm{mm}$

Fig. 1 Size and shape of specimens.

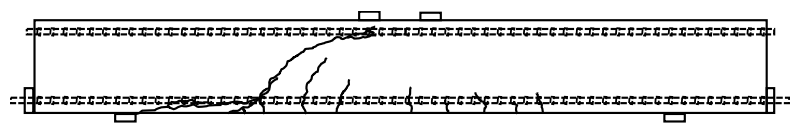

(a) $\mathrm{N}$

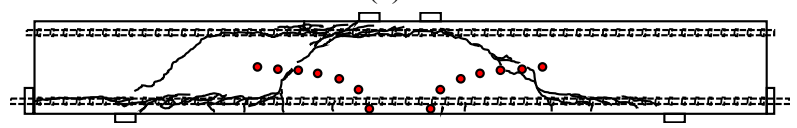

(b) M1

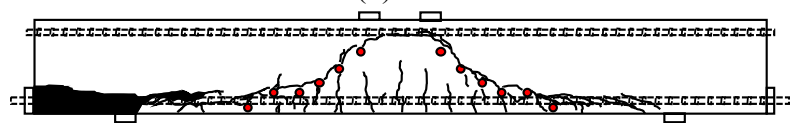

(c) M2

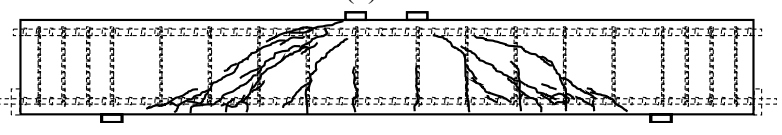

(d) $\mathrm{RN}$

Fig. 3 Crack distribution maps at failure.

Table 1 Experimental cases.

\begin{tabular}{|c|l|c|c|c|}
\hline Name & Main reinforcement ratio (\%) & Shear reinforcement ratio (\%) & Compressive strength of concrete (MPa) & Strength (kN) \\
\hline $\mathrm{N}$ & & & 24.6 & 44.9 \\
\hline M1 & 1.70 & 0.00 & 37.7 & 63.8 \\
\hline M2 & & & 39.7 & 99.8 \\
\hline RN & & 0.47 & 34.0 & 155.8 \\
\hline
\end{tabular}




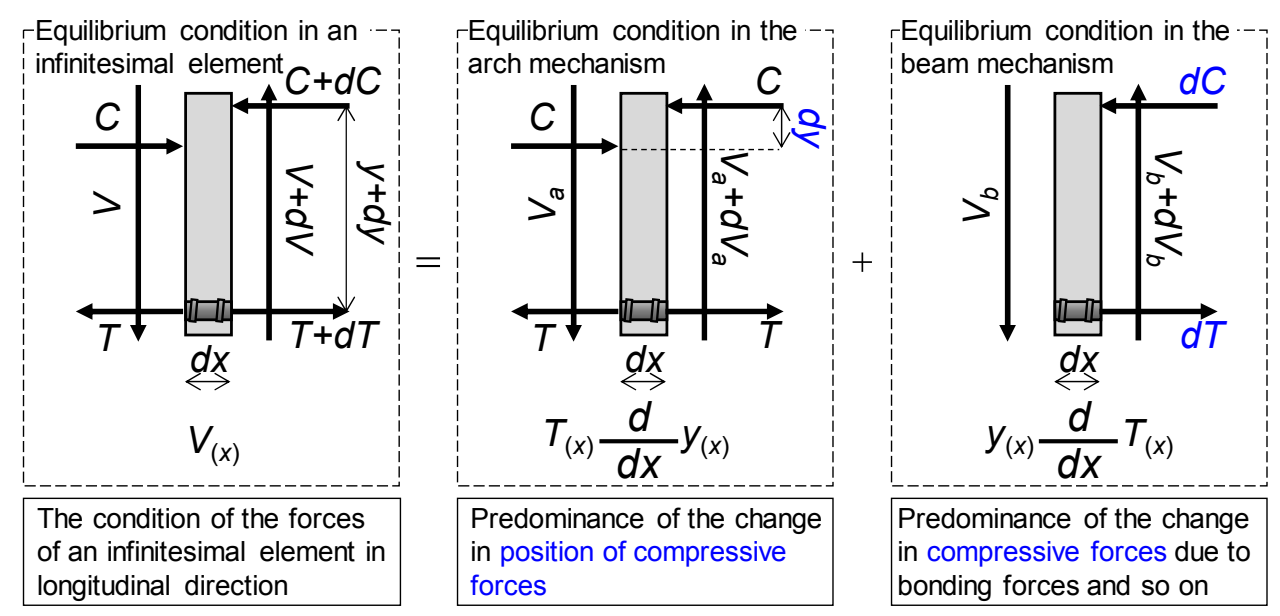

Fig. 4 Equilibrium conditions of arch and beam mechanisms in an infinitesimal element.

along the tensile rebars [Fig. 3(c)]. In the case of RN, the first diagonal crack occurred at around 45 to $50 \mathrm{kN}$. After that, it failed in a diagonal cracking failure at $155.8 \mathrm{kN}$ with propagations of multiple diagonal cracks [Fig. 3(d)].

From a previous study, it is known that the shear capacities of beams can be estimated by assuming that the capacities are proportional to $f_{c}^{1 / 3}\left(f_{c}\right.$ : compressive strength of concrete) (Okamura and Higai 1980). Using this fact, the shear capacities in the experiments were normalized based on the compressive strength of $\mathrm{N}$ by multiplying each capacity obtained in the experiments by $\left(24.6 / f_{c}\right)^{1 / 3}$. The normalized capacities were $55.3 \mathrm{kN}$ for M1 and 85.1 $\mathrm{kN}$ for M2. Consequently, it was confirmed that an increase of more than $190 \%$ in the shear capacity for $\mathrm{N}$ could be expected by applying multiple holes.

\subsection{Load carrying mechanism}

To determine why the shear capacities increased in the case of M1 and M2, the contributions of load carrying mechanisms were calculated. It is a well-known fact that the shear force can be decomposed into the contributions of arch mechanisms $\left(V_{a}\right)$ and beam mechanisms $\left(V_{b}\right)$ (Park and Paulay 1975). $V_{a}$ and $V_{b}$ can be obtained from the first order differential of the cross-sectional moment and the equilibrium condition of an infinitesimal element, as shown in Fig. 4. From Fig. 4, it can be understood that $V_{a}$ is caused by changes in positions of the compressive forces and that $V_{b}$ is caused by changes in the magnitude of the compressive forces. Here, $V_{a}$ and $V_{b}$ were calculated using the following equation proposed in a previous study (Yamada 2019):

$$
\begin{gathered}
V_{a}=V \log _{\left(\frac{\xi_{i}}{\xi_{j}}\right)} \frac{\xi_{i} \varepsilon_{\left(\xi_{j}\right)}}{\xi_{j} \varepsilon_{\left(\xi_{i}\right)}} \\
V_{b}=V \log \left(\frac{\xi_{i}}{\xi_{j}}\right) \frac{\varepsilon_{\left(\xi_{i}\right)}}{\varepsilon_{\left(\xi_{j}\right)}}
\end{gathered}
$$

where $V$ : applied shear force; $\xi_{i}$ and $\xi_{j}$ : positions along tensile rebar from the supporting points; and $\varepsilon$ : rebar strains.

The derivation procedures are shown in Fig. 5. $V_{a}$ and $V_{b}$ were calculated from two points of rebar strain in each section and were averaged in the shear span to obtain $V_{a}$ and $V_{b}$ between the supporting points and loading points. The contribution of the stirrup $\left(V_{b s}\right)$ was calculated from the averaged strains of stirrups based on the assumptions that the angle of idealized truss members was $45^{\circ}$ and that $V_{b}$ could be expressed as a linear summation of the contribution of concrete $\left(V_{b c}\right)$ and the contribution of the $\operatorname{stirrup}\left(V_{b s}\right)$.

The results of decomposition are shown in Fig. 6. In all cases, $V_{b}$ decreased when the load reached around 40 to $50 \mathrm{kN}$ and after that, $V_{a}$ was predominant. In the case of RN, after the predominance of $V_{a}, V_{b c}$ was maintained at around $20 \mathrm{kN}$ with the appearance of $V_{b s}$ owing to the confinement effect of the stirrup. This phenomenon has been confirmed in previous studies, for example, the study of Nakamura et al. (2018). In the case of M1 and $\mathrm{M} 2$, the magnitude of $V_{a}$ showed a higher value than that of $\mathrm{N}$ when the loads reached their maximum in each case. It was confirmed that the multiple holes in the case of M1 and M2 increased the shear capacity owing to the predominance of $V_{a}$.

To clarify the interactions between cracks due to aging deterioration and the existence of the holes, nonlinear FE analyses were conducted for the beams in the experiments.

\section{Interactions between cracks and existence of multiple holes}

\subsection{Analytical overview}

Three-dimensional nonlinear FE analyses were conducted by using COM3 in this study. An orthogonal two-way fixed crack model was applied as the FE model. The model could represent the occurrence of active cracks that generated strong nonlinearity on the elements The compressive constitutive law proposed by Maekawa et al. (2003) was applied. 
The size and shape of the analytical models are illustrated in Fig. 7. The vertical cracks that modeled the corrosion cracks along all stirrups and the horizontal cracks that modeled the cracks along tensile rebars were examined. The crack widths of these artificial cracks were adopted as the analytical parameters (Table 2). The artificial cracks were expressed by applying interface elements in the analytical models. The interface elements had no interstice between nodes before loading, and the volume of these elements was zero. To introduce a simplified corrosion crack model, the corrosion-induced stresses around the rebars were not considered in this study. Even if the corrosion cracks are modeled in this method, previous studies confirmed that the macroscopic behavior of the deteriorated beams with extreme corrosion cracks can be reproduced (Yamada 2018a; Yamada et al. 2018).

The crack widths were controlled as changes in the shear stiffnesses on the surface of the interface elements, and the stiffnesses were converted into equivalent crack widths based on the proposed equation in a previous study (Aoyagi and Yamada 1983). The previous study

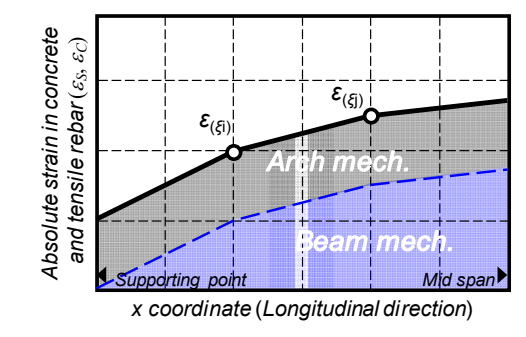

$\left[\begin{array}{c}\text { Contributing ratios of arch and beam mechanisms } \\ \text { Arch mechanism } \\ P_{a}=\log _{\left(\frac{\xi_{i}}{\xi_{j}}\right) \frac{\xi_{i} \varepsilon_{(\xi)}}{\xi_{j} \varepsilon_{(\xi i)}}} \\ \text { Beam mechanism } \\ P_{b}=\log _{\left(\frac{\xi_{i}}{\xi_{j}}\right)} \frac{\varepsilon_{\left(\xi_{i}\right)}}{\varepsilon_{(\xi)}} \text { Salculated by rebar } \\ \text { strains on 2 positions }\end{array}\right]$

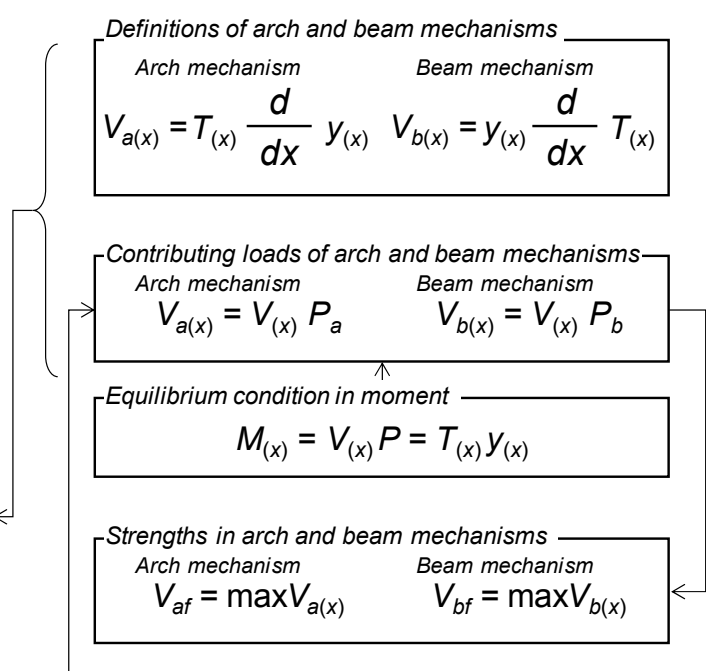

Fig. 5 Procedures for theoretical solutions of $V_{a}$ and $V_{b}$.
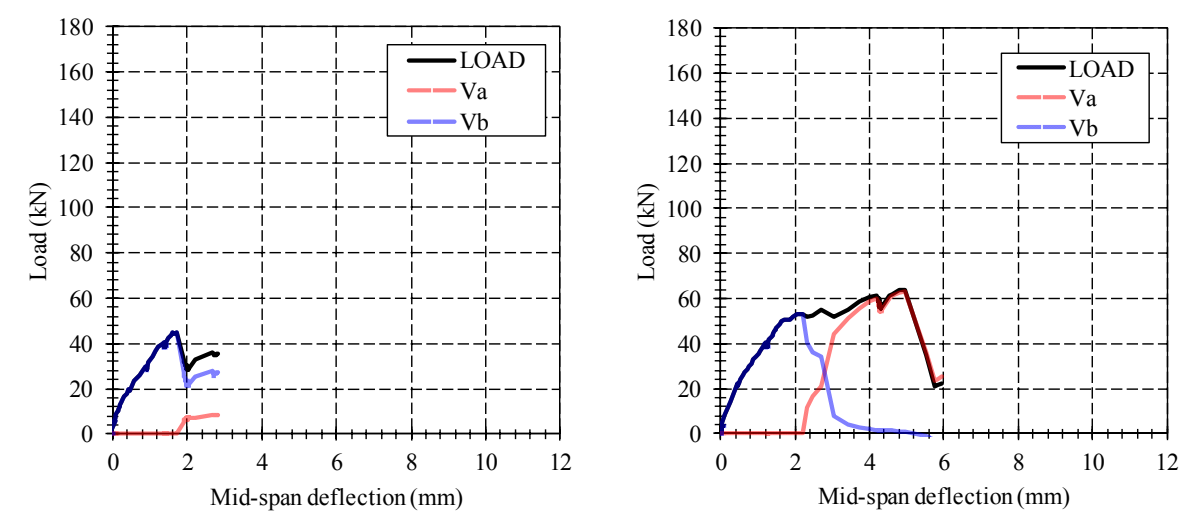

(a) $\mathrm{N}$

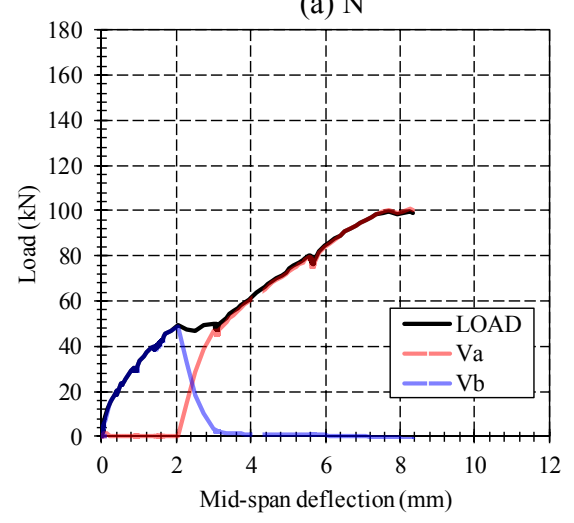

(c) M2

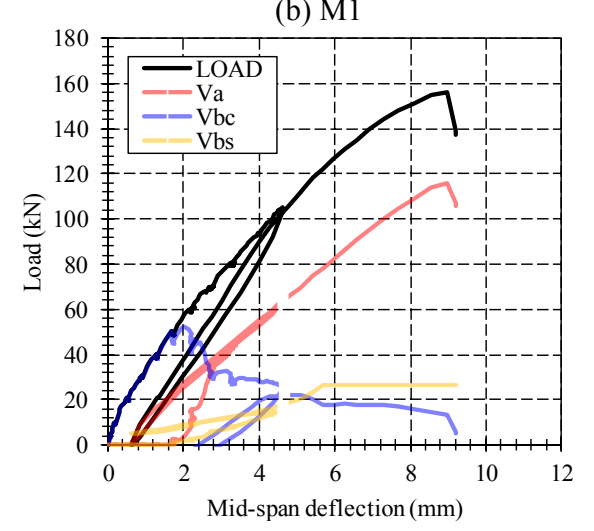

(d) $\mathrm{RN}$

Fig. 6 Decomposition results of arch and beam mechanisms in the experiments. 
Table 2 Analytical case.

\begin{tabular}{|c|c|c|c|c|}
\hline \multirow[b]{2}{*}{ Name } & \multirow{2}{*}{$\begin{array}{c}\text { Positions of } \\
\text { artificial crack }\end{array}$} & \multirow{2}{*}{$\begin{array}{l}\text { Equivalent crack width }(\mathrm{mm}) \\
\text { (Shear stiffness of cracks } \\
\left.\left(\mathrm{N} / \mathrm{mm}^{2} / \mathrm{mm}\right)\right)\end{array}$} & \multicolumn{2}{|c|}{ Properties of interface element $\left(\mathrm{N} / \mathrm{mm}^{2} / \mathrm{mm}\right)$} \\
\hline & & & Positions of artificial crack & Positions of loading plates \\
\hline $\mathrm{N}-\mathrm{S}$ & \multirow{6}{*}{ along stirrups } & \multirow[b]{2}{*}{$0.0\left(9.8 \times 10^{8}\right)$} & \multicolumn{2}{|c|}{ Normal stiffness in closure mode } \\
\hline M1-S & & & 9.8 & 980.0 \\
\hline M2-S & & \multirow[b]{2}{*}{$0.3(11.7)$} & \multicolumn{2}{|c|}{ Shear stiffness in closure mode } \\
\hline RN-S & & & $9.8 \times 10^{8}, 11.7,7.0,3.5,0.7$ & 9.8 \\
\hline RM1-S & & \multirow[b]{2}{*}{$0.5(7.0)$} & \multicolumn{2}{|c|}{ Normal stiffness in opening mode } \\
\hline RM2-S & & & 0.1 & 0.1 \\
\hline N-T & \multirow{5}{*}{$\begin{array}{l}\text { along tensile } \\
\text { rebars }\end{array}$} & \multirow{2}{*}{$1.0(3.5)$} & \multicolumn{2}{|c|}{ Shear stiffness in opening mode } \\
\hline M1-T & & & 0.1 & 0.1 \\
\hline $\begin{array}{l}\text { M2-T } \\
\text { RN-T }\end{array}$ & & $5.0(0.7)$ & \multicolumn{2}{|c|}{ Friction coefficients of interface element } \\
\hline RM1-T & & \multirow{2}{*}{ for each case } & Positions of artificial crack & Positions of loading plates \\
\hline RM2-T & & & 0.6 & 0.9 \\
\hline
\end{tabular}
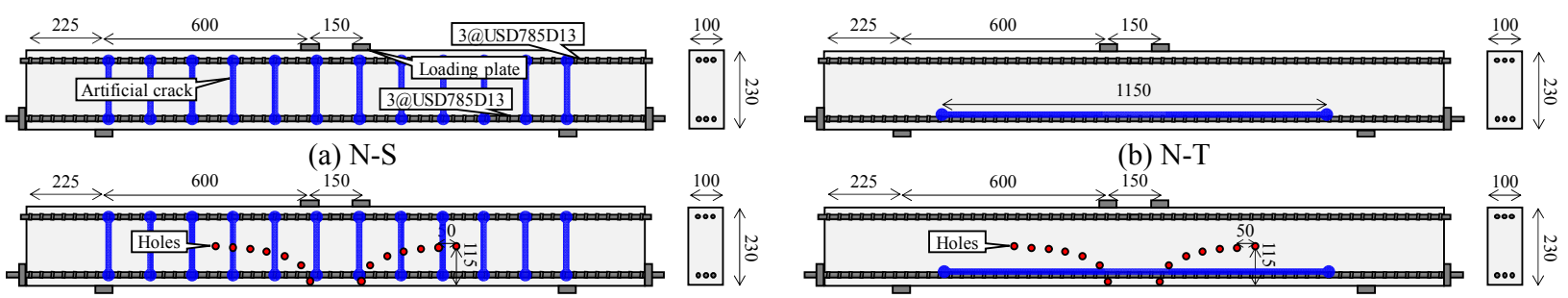

(b) N-T
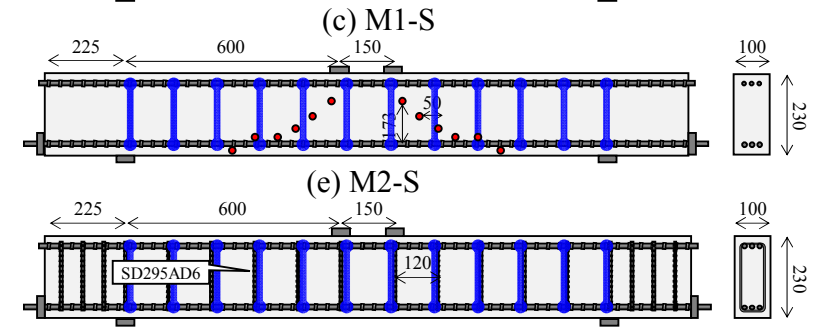

(g) RN-S
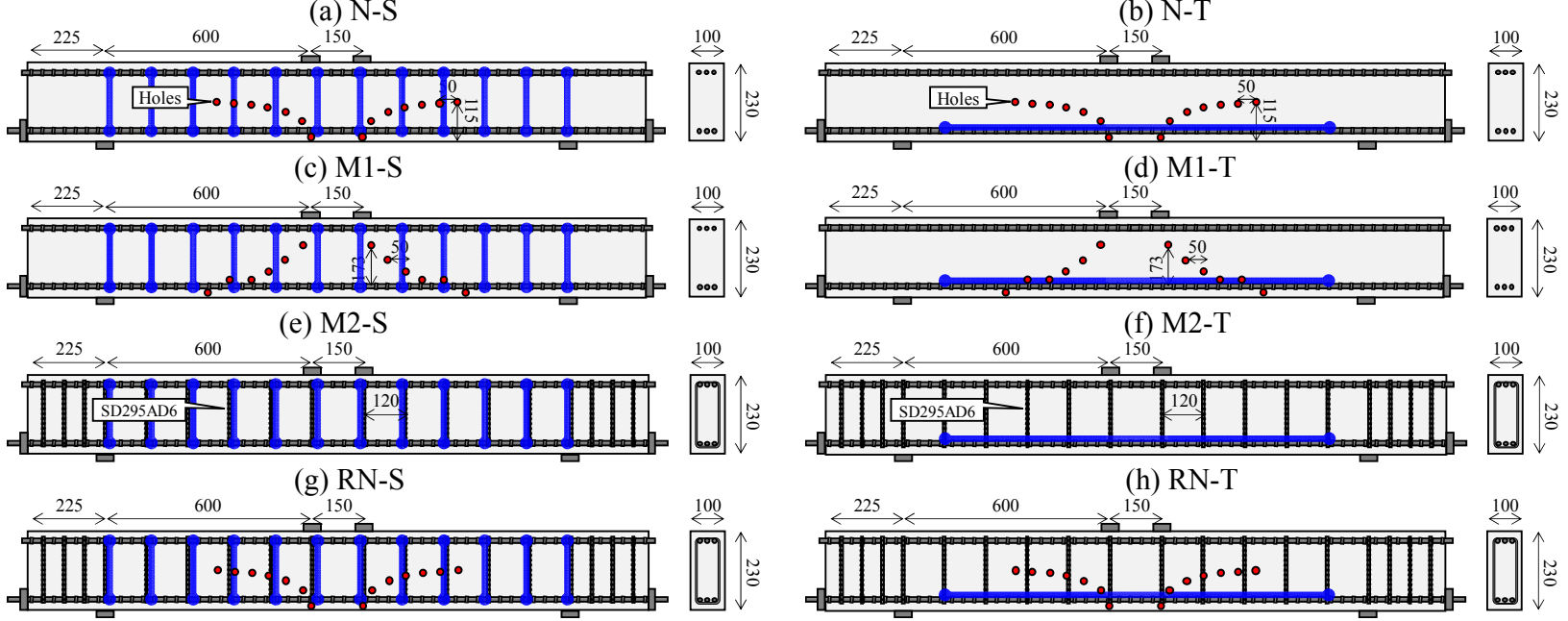

(i) RM1-S
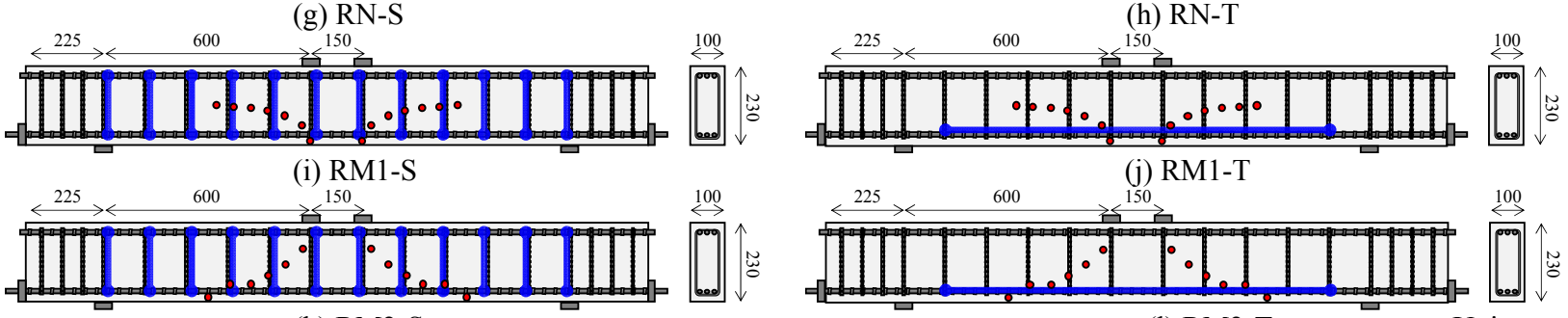

(k) RM2-S

Fig. 7 Size and shape of analytical models.

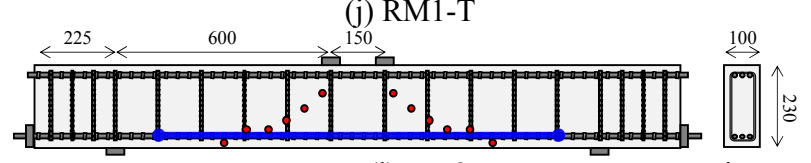

(1) RM2-T

Unit: $\mathrm{mm}$

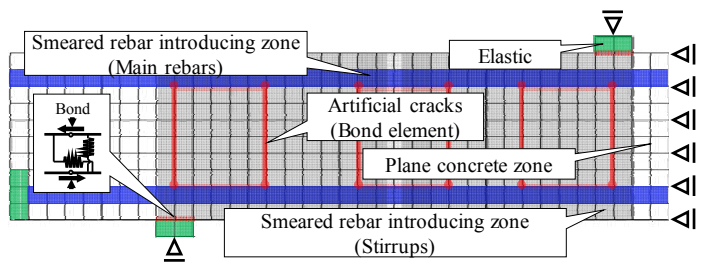

(a) Case with cracks along stirrups

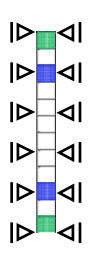

$\triangleright \mathbb{M}^{\prime} \triangleleft \mid$

Fig. 8 Analytical mesh models.

aimed to introduce a 10 to $20 \%$ weight loss in the rebars, and the crack widths were distributed in the range of 0.00 to $1.00 \mathrm{~mm}$ (Ullah et al. 2016). However, to simulate the most severe state of corrosion, an equivalent crack width of $5.00 \mathrm{~mm}$ was included in the analytical case of this

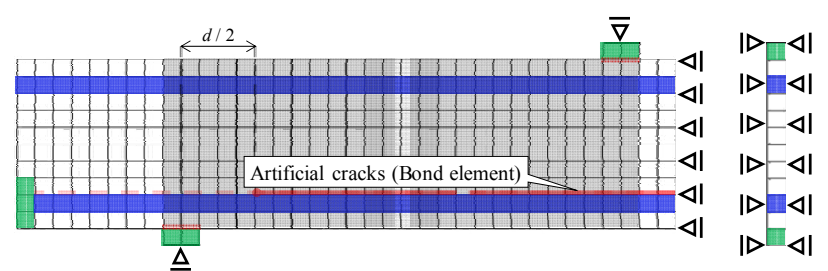

(b) Case with a crack along tensile rebars study. To investigate the fundamental interactions between vertical cracks and holes without stirrups, N-S, M1-S, and M2-S were included in the analytical cases.

The analytical mesh models are shown in Fig. 8. Eight-node quadratic isoparametric elements of $25 \mathrm{~mm}$ 
in length in all directions were applied, and the models were restricted to be perpendicular to the longitudinal direction of the beams to accelerate the calculation speed. The exponential model proposed by Maekawa et al. (2003) was applied to express the tension-softening behaviors of concrete. The indices to fix the model were calculated by using the evaluating equation of fracture energy in the $f i b$ (Fédération Internationale du Béton) model code (fib 2010). The Mohr-Coulomb linear friction law was applied as the properties of interface elements shown in Fig. 9. The properties of the interface elements are listed in Table 2. The opening and sliding of the interface elements were fixed in the position where the stirrups crossed the artificial cracks to express the dowel actions of the stirrups. The holes in the beams were reproduced by removing FE elements at the positions of the holes. There was a difference in the shape of the holes between the experiment and analysis; however, the influence of the difference was negligibly small, as
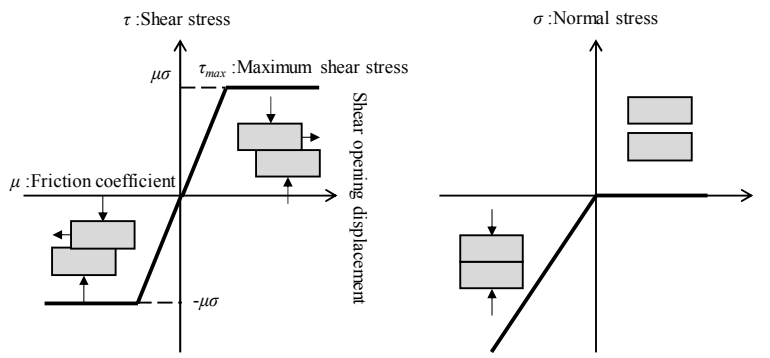

Fig. 9 Properties of interface elements.

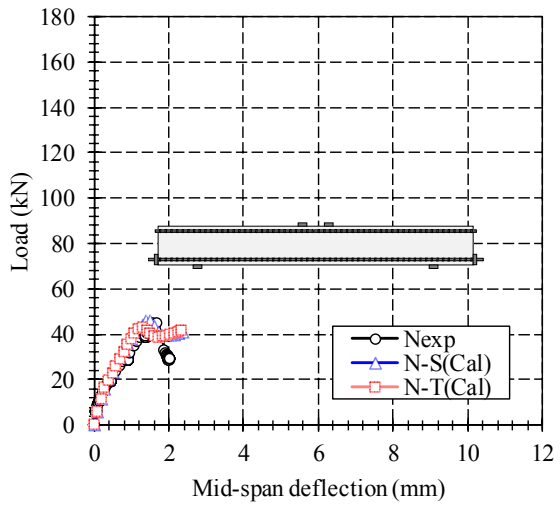

(a) $\mathrm{N}$

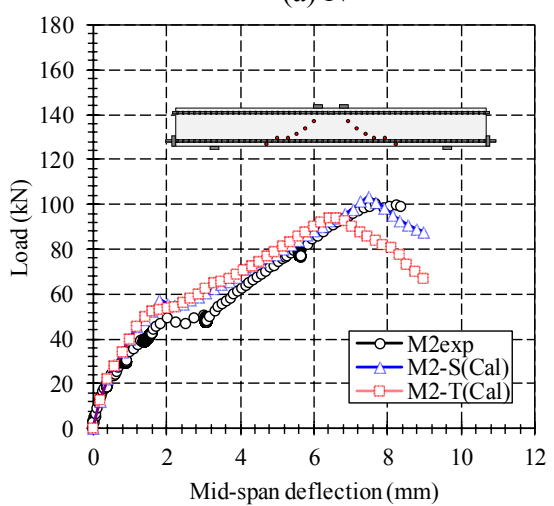

(c) M2 discussed below. Displacements of less than $0.01 \mathrm{~mm} / \mathrm{s}$ were applied to conduct the static analyses.

\subsection{Validity of analytical models}

Reproducing analyses of the experimental results were conducted by using the two models shown in Fig. 8 when the equivalent crack width was $0.0 \mathrm{~mm}$. The load deflection curves are shown in Fig. 10. The analytical results agreed well with the experimental results in all cases.

The maximum principal strain distributions and crack distribution maps at failure are shown in Fig. 11. In the case of N-S and N-T, although the angles of strain were steeper than those of diagonal cracks, it was confirmed that the analytical results could reproduce the crack distributions and failure modes.

Therefore, this study proceeded to investigate the interactions between artificial cracks, the equivalent width, and the existence of the holes by using these analytical models.

\subsection{Effects of equivalent crack width and hole positions on shear capacity of RC beams}

The strengths obtained from the analytical results are listed in Table 3, and the relationships between the strength ratios and equivalent crack widths are shown in Fig. 12. The strength ratios were defined as the ratios of the shear strength of each beam to that of beams without holes and artificial cracks. The differences in the strength ratios after crack widths of $0.3 \mathrm{~mm}$ were relatively small

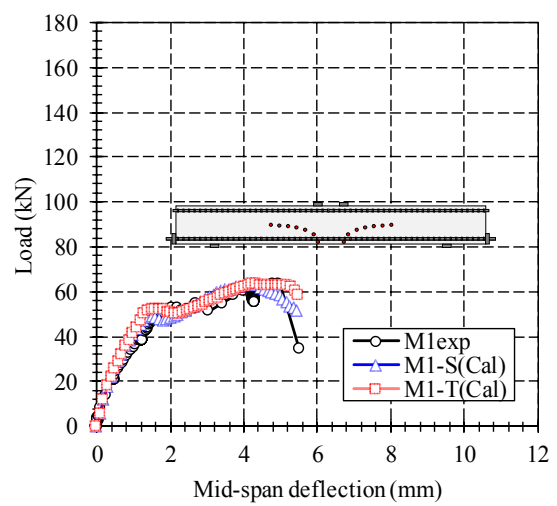

(b) M1

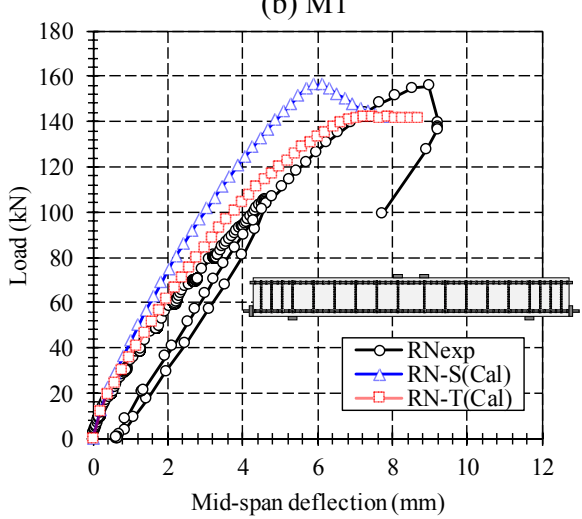

(d) $\mathrm{RN}$

Fig. 10 Reproducibility in load deflection curves. 


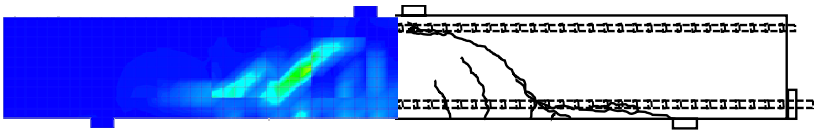

(a) N-S

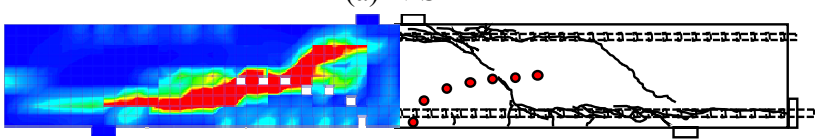

(c) M1-S

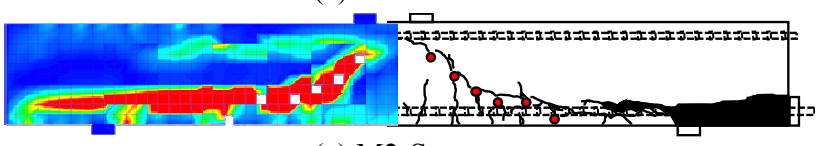

(e) M2-S

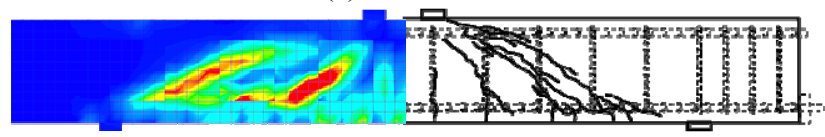

(g) RN-S

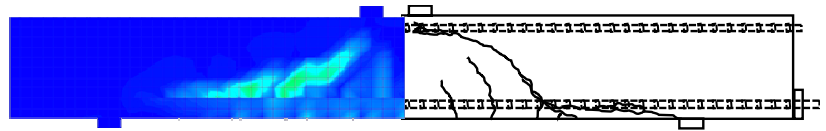

(b) N-T

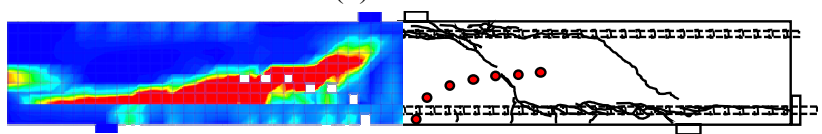

(d) M1-T

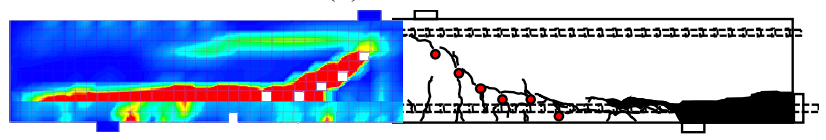

(f) M2-T

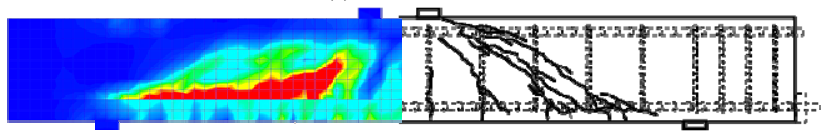

(h) RN-T

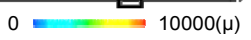

Fig. 11 Maximum principal strain distributions at failure.

Table 3 Analytical results.

\begin{tabular}{|c|c|c|c|c|c|}
\hline \multicolumn{5}{|c|}{ Strength $(\mathrm{kN}) /$ Strength ratio } \\
\hline \multirow{2}{*}{ Name } & \multicolumn{5}{|c|}{ Equivalent crack width $(\mathrm{mm}) /$ Shear stiffness of cracks $(\mathrm{N} / \mathrm{mm} 2 / \mathrm{mm})$} \\
\cline { 2 - 6 } & $0.0 / 9.8 \times 10^{8}$ & $0.3 / 11.7$ & $0.5 / 7.0$ & $1.0 / 3.5$ & $5.0 / 0.7$ \\
\hline N-S & $45.9 / 1.0$ & $26.5 / 0.6$ & $27.9 / 0.6$ & $26.7 / 0.6$ & $26.7 / 0.6$ \\
\hline M1-S & $63.3 / 1.4$ & $49.3 / 1.1$ & $47.7 / 1.1$ & $48.9 / 1.1$ & $49.1 / 1.1$ \\
\hline M2-S & $103.6 / 2.3$ & $35.6 / 0.8$ & $35.8 / 0.8$ & $37.5 / 0.8$ & $34.8 / 0.8$ \\
\hline RN-S & $156.3 / 1.0$ & $110.3 / 0.7$ & $110.5 / 0.7$ & $107.9 / 0.7$ & $91.2 / 0.6$ \\
\hline RM1-S & $133.5 / 0.9$ & $93.6 / 0.6$ & $87.7 / 0.6$ & $90.0 / 0.6$ & $85.5 / 0.5$ \\
\hline RM2-S & $152.6 / 1.0$ & $107.0 / 0.7$ & $106.7 / 0.7$ & $104.4 / 0.7$ & $85.8 / 0.6$ \\
\hline N-T & $44.2 / 1.0$ & $59.6 / 1.3$ & $57.5 / 1.3$ & $59.3 / 1.3$ & $59.3 / 1.3$ \\
\hline M1-T & $63.4 / 1.4$ & $72.1 / 1.6$ & $72.2 / 1.6$ & $71.8 / 1.6$ & $71.7 / 1.6$ \\
\hline M2-T & $94.1 / 2.1$ & $114.8 / 2.6$ & $109.5 / 2.4$ & $100.4 / 2.2$ & $109.2 / 2.4$ \\
\hline RN-T & $142.1 / 0.9$ & $127.2 / 0.8$ & $133.9 / 0.9$ & $131.1 / 0.8$ & $123.0 / 0.8$ \\
\hline RM1-T & $124.3 / 0.8$ & $116.3 / 0.7$ & $122.9 / 0.8$ & $121.0 / 0.8$ & $129.1 / 0.8$ \\
\hline RM2-T & $111.8 / 0.7$ & $119.7 / 0.8$ & $116.2 / 0.7$ & $108.5 / 0.7$ & $119.1 / 0.8$ \\
\hline
\end{tabular}

in all cases. Several experimental results indicated that reductions in the flexural performances of beams that had a crack width greater than $1.28 \mathrm{~mm}$ were almost similar (Ou and Chen 2014), and that 10 to $30 \%$ of the shear strengths decreased by less than $0.20 \mathrm{~mm}$ of the averaged corrosion crack width (Xia et al. 2011). From these results, it can be deduced that the losses in the shear strengths occurred by less than $1 \mathrm{~mm}$ of the crack width. Thus, it can be considered that this analytical tendency was one of the rational results. In addition, it is known that not only corrosion cracks but also thermal cracks (Khan et al. 2010) and drying shrinkage cracks (Nakarai et al. 2016; Sasano et al. 2018) affect the capacities of concrete structural members. Thus, it can be considered that the following discussion is applicable to beams with thermal cracks and drying shrinkage cracks.

In examining the figures, there were tendencies in which the ratios of beams with horizontal artificial cracks had higher values than beams without cracks, and that the ratios of beams with vertical artificial cracks were lower than those of beams without cracks. It can be considered that these phenomena were caused by changes in $V_{a}$, which was affected by the formations of compressive struts because strong compressive struts were formed in the case with horizontal cracks. By contrast, formations were prevented by cracks in the case with vertical cracks. Moreover, increases in the strengths of beams with corrosion crack widths of 0.25 to $0.83 \mathrm{~mm}$ along the tensile rebar were confirmed by several studies, for example, the study by Ith et al. (2014).

In the case without stirrups [Figs. 12(a) and (b)], increases in the ratios for cases with cracks were confirmed owing to the existence of multiple holes. In particular, in the case of M1 [Fig. 12(a)], the strength ratios recovered by more than 1.0 owing to the contributions of the holes, and the ratios tended to approximately 1.1 in the case with vertical cracks and approximately 1.6 in the case with horizontal cracks. In the case of M2 [Fig. 12(b)], the ratios increased by more than 1.0 only in the case with horizontal cracks. The ratios in the case with horizontal cracks were higher than 2.0. However, the ratios in the case with vertical cracks were approximately 0.8 . The flexural capacity of $\mathrm{M} 2$ was approximately 2.5 times that of $\mathrm{N}$, and the order of this value almost coincided with the strength ratios. Thus, it can be considered that the capacity was reached at the flexural capacity by the existence of holes and artificial cracks in the case of M2. Meanwhile, the failure loads were lower than $40 \%$ of the 
flexural capacity in the case of M1.

By contrast, in the case with stirrups [Fig. 12(c)], the strength ratios were lower than 1.0 regardless of the existence of holes, and the tendencies of the ratios were mainly characterized by the positions of the artificial cracks. This phenomenon can be explained by the confinement effect of the stirrups. It can be considered that the formation characteristics of the compressive struts were not affected by the existence of holes because the deformation caused by the holes was confined by the stirrups.

To clarify why these phenomena occurred, the load carrying mechanisms were investigated based on the stress distributions. The case of $5.0 \mathrm{~mm}$ of equivalent crack width was targeted in the following discussion because differences in the load carrying mechanisms in cases with crack widths greater than $0.3 \mathrm{~mm}$ were relatively small.

\section{Clarifications of load carrying mechanisms}

\subsection{Decomposition method of load carrying mechanisms in analyses}

To clarify the load carrying mechanisms, $V_{a}$ and $V_{b}$ for each beam were calculated based on longitudinal stress distributions obtained from the analytical results. The concept of calculations is illustrated in Fig. 13 (Yamada 2018a). $V_{a}$ and $V_{b}$ were calculated by the discrete formula shown in the figure. The magnitudes of the compressive and tensile forces were calculated by trapezoidal integration of the compressive and tensile stresses obtained at the Gaussian integral points. The positions where the moments caused by the stress distributions on the compressive side and tensile side converged to zero were defined as the acting positions of the resultant forces. The neutral axes were obtained as the positions where the magnitudes of stresses were equal to zero. The stresses of interface elements were removed during calculation. In this study, changes in the positions of resultant tensile forces were considered because the FE models were smeared crack models. The calculated $V_{a}$ and $V_{b}$ were averaged in the shear span except for the positions of loading plates.

The representative decomposition results in the load deflection curves are shown in Fig. 14. The summation of $V_{a}$ and $V_{b}$ agreed well with the analytical loads in each case. In the case of N-T, which had artificial cracks along the tensile rebar, $V_{a}$ was predominant owing to a loss of bonding force. In the case of RM2-S and RM1-T, $V_{b}$ tended to appear relatively higher owing to the contriution of the stirrups. Therefore, the validity of the decomposition methods was confirmed. Accordingly, the relationship between the tendencies of $V_{a}$ and $V_{b}$ and minimum principal stress distributions that represent the characteristics of compressive struts were examined.

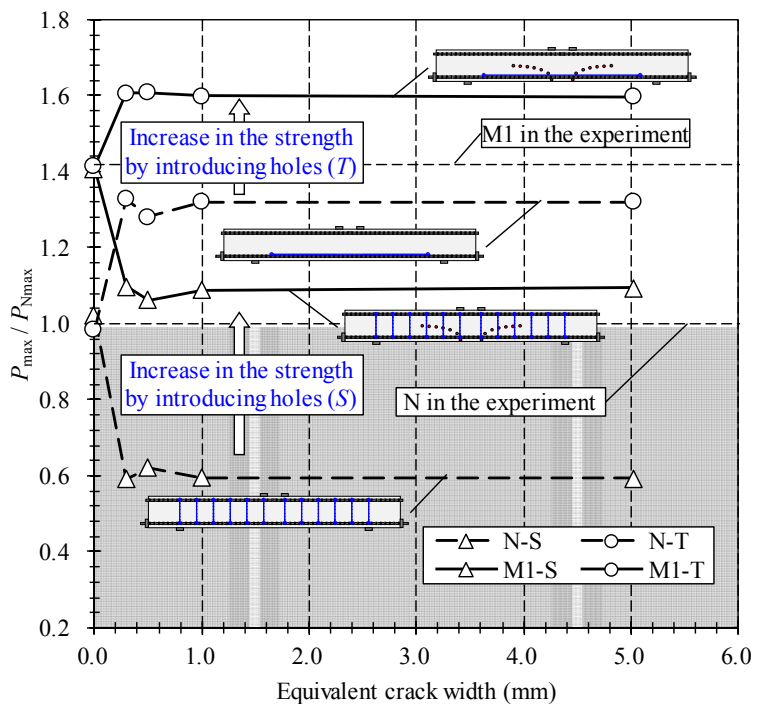

(a) Case of M1 without stirrups

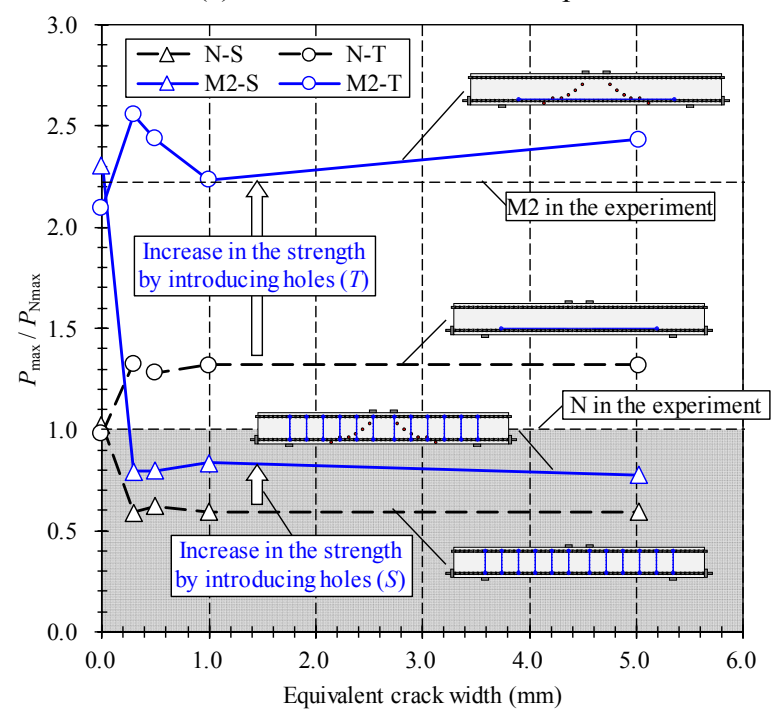

(b) Case of M2 without stirrups

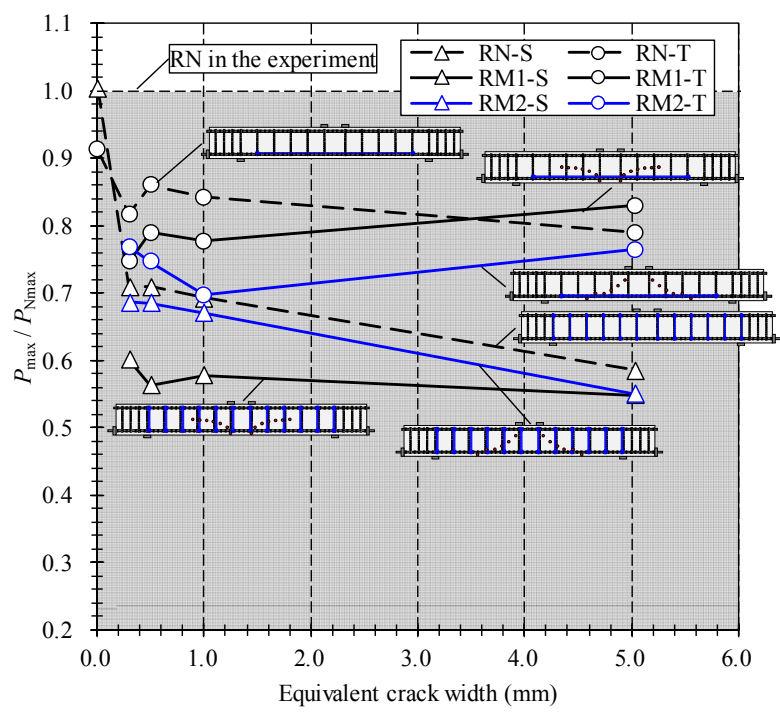

(c) Case of M1 and M2 with stirrups

Fig. 12 Strength ratios for the beams without hole. 


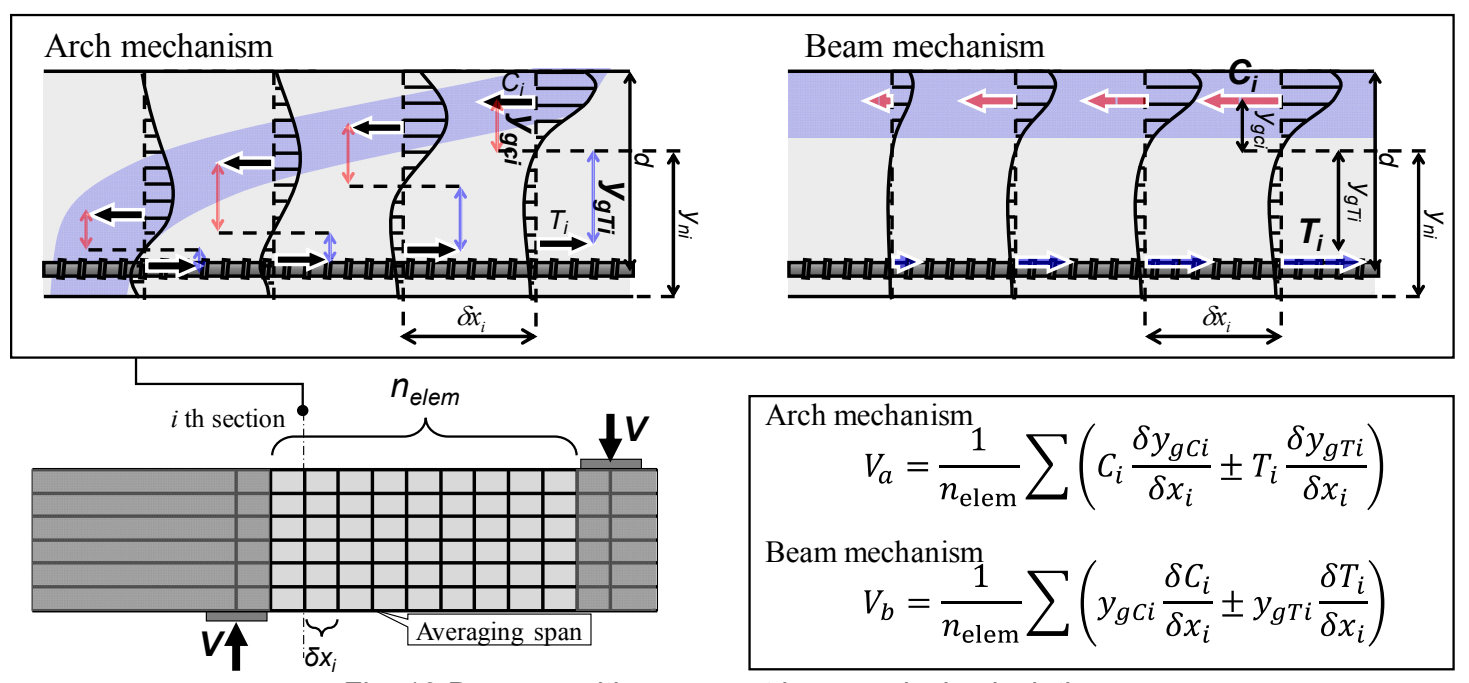

Fig. 13 Decomposition concept in numerical calculations.

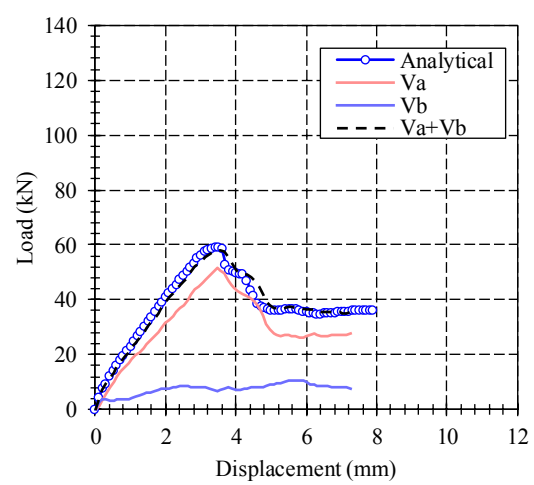

(a) N-T

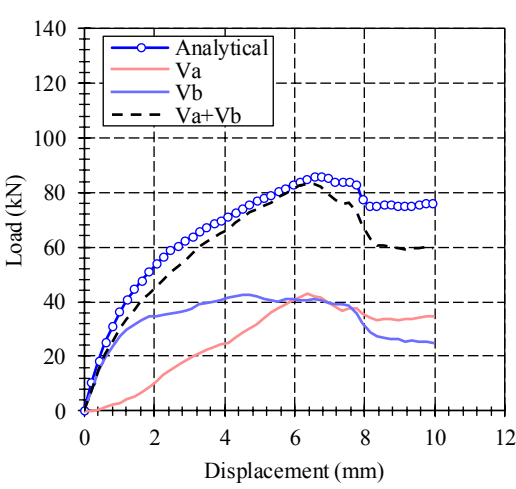

(b) RM2-S

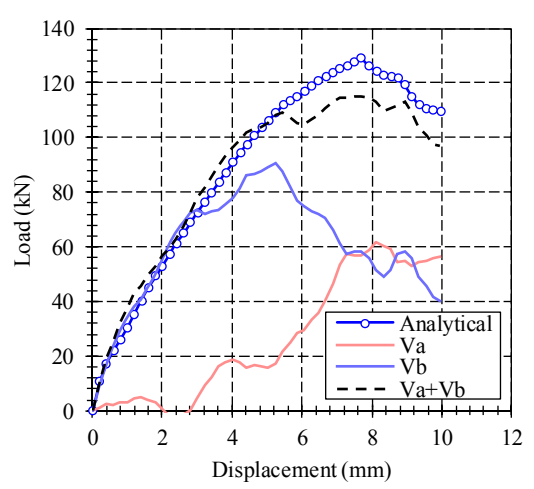

(c) RM1-T

Fig. 14 Representative decomposition results in numerical calculations (in case of $5.0 \mathrm{~mm}$ of crack width).

\subsection{Effect of interactions between artificial cracks and multiple holes on load carrying mechanisms}

The tendencies of $V_{a}$ and $V_{b}$ vs. the applied load are shown in Fig. 15. In the case of beams with vertical artificial cracks without stirrups, $V_{a}$ appeared after $V_{b}$ decreased. In the cases of N-S and M2-S, the loads reached around 40 to $50 \mathrm{kN}$ with similar load carrying mechanisms [Figs. 15(a) and (c)]. Meanwhile, in the case of M1-S, the load increased with the predominance of $V_{a}$ [Fig. 15(b)]. This might be caused by the formation of compressive struts owing to the holes of M1. For beams with horizontal artificial cracks without stirrups, $V_{a}$ was predominant. This phenomenon, which has been observed in several studies, for example, that of Yamada (2018a), might be caused by a loss of bonding forces between concrete and tensile rebars. In the cases of N-T and M1-T, the loads reached around 60 to $70 \mathrm{kN}$ owing to the predominance of $V_{a}$ [Figs. 15(d) and (e)]. In the case of M2-T, the magnitude of $V_{a}$ was larger than that in the case of N-T and M1-T. Consequently, the load reached more than $100 \mathrm{kN}$ [Fig. 15(f)]. This phenomenon might be caused by formations of wider compressive struts owing to the holes of M2.

For beams with stirrups, the tendencies of the load carrying mechanism were similar in each case with vertical and horizontal artificial cracks. In the case of RN-S, RM1-S, and RM2-S, $V_{b}$ appeared larger than that of the case without stirrups; and in the case of RN-T, RM1-T, and RM2-T, $V_{b}$ was predominant. It was considered that this predominance was caused by the dowel actions of the stirrups, which generated differences in the tensile forces in the longitudinal directions of the beams, and that the magnitudes of $V_{b}$ were overestimated in these analyses because the deformations of interface elements were fixed at the positions of the stirrups across the horizontal artificial cracks.

\subsection{Relationships between load carrying mechanisms and appearance characteristics of compressive strut}

It was indicated that the load carrying mechanisms were affected by the positions of the holes for beams without stirrups; moreover, the mechanisms of beams with stirrups were not affected by holes because of the confinement effect of the stirrups. To confirm these phenomena, the minimum principal stress distributions were examined. The minimum principal stress distributions at failure for an equivalent crack width of $5.0 \mathrm{~mm}$ are shown in Fig. 16. For beams with vertical artificial cracks without 


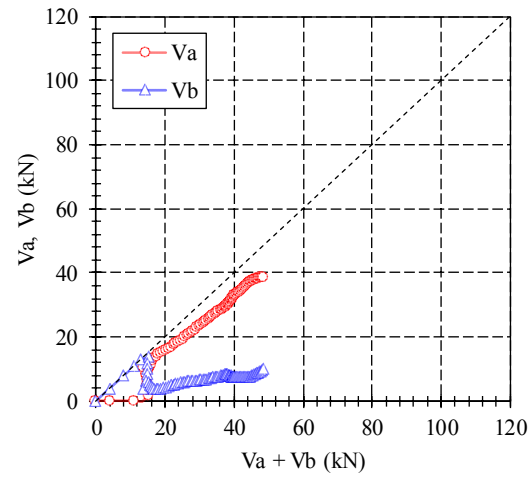

(a) N-S

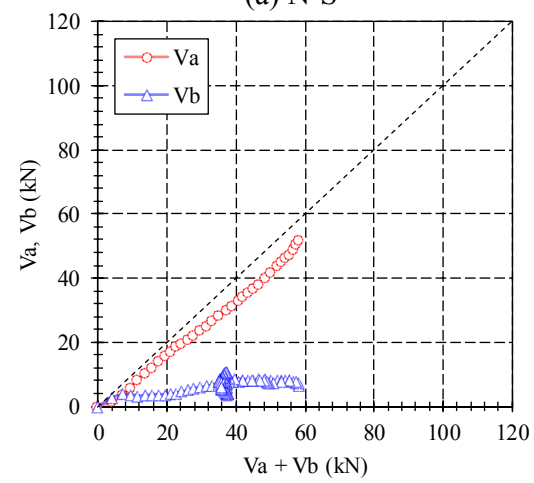

(d) N-T

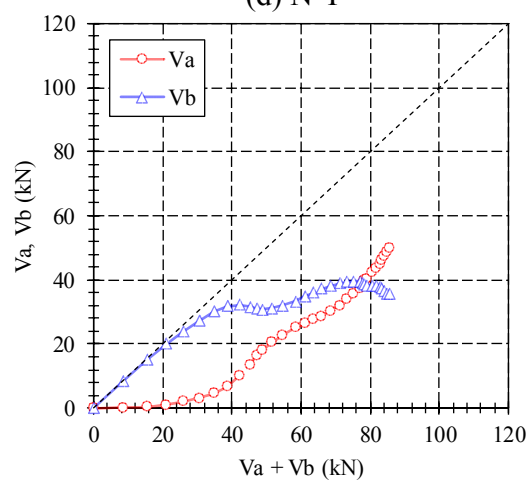

(g) RN-S

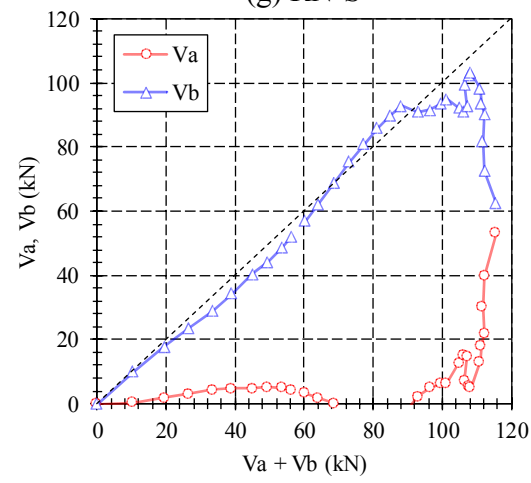

(j) RN-T

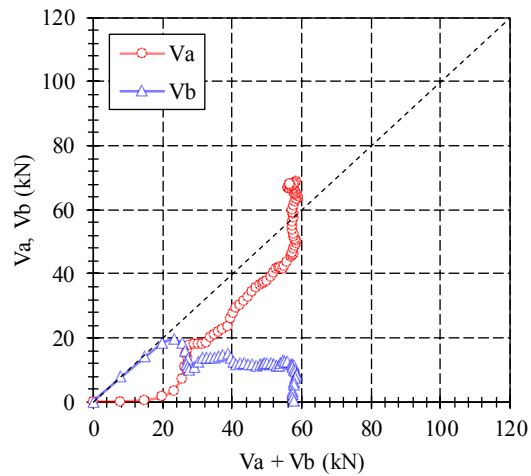

(b) M1-S

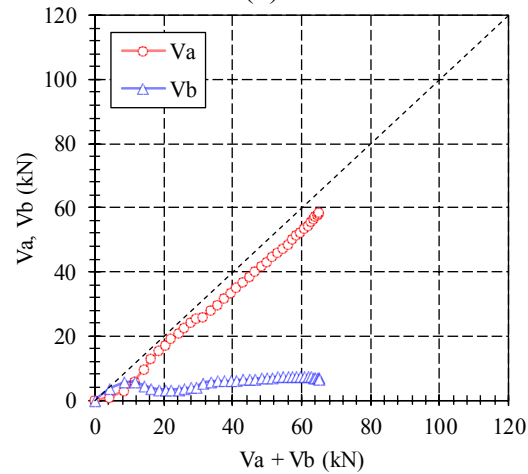

(e) M1-T

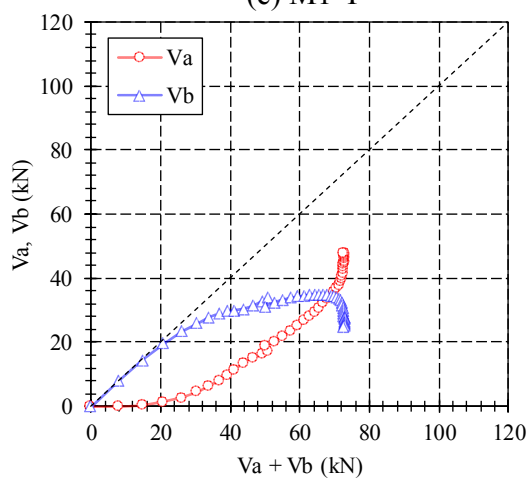

(h) RM1-S

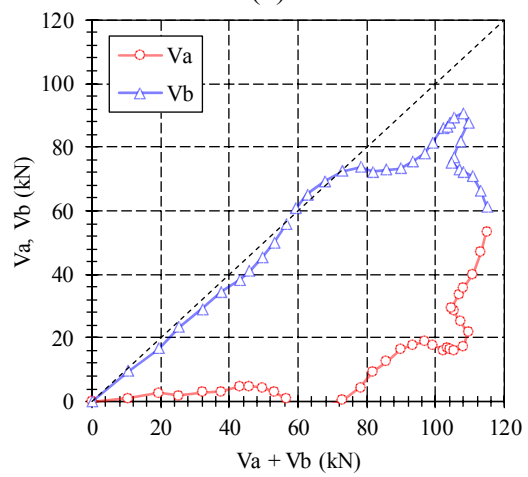

(k) RM1-T

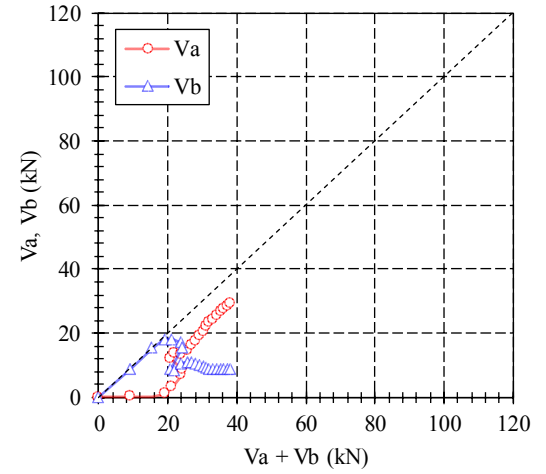

(c) M2-S

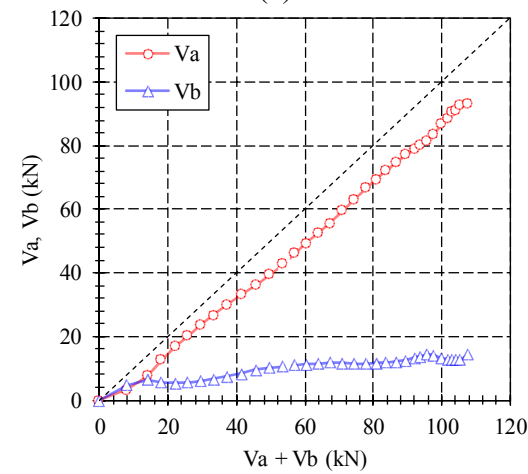

(f) M2-T

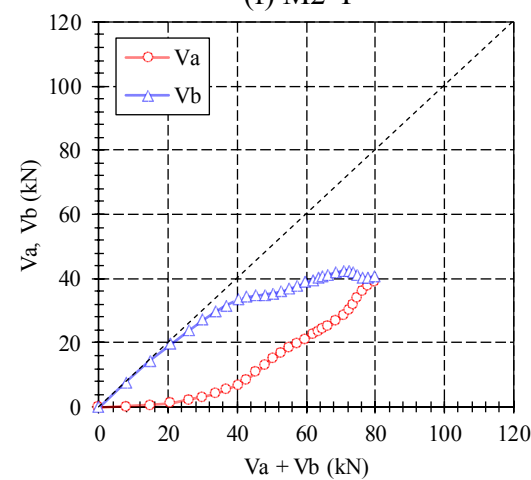

(i) RM2-S

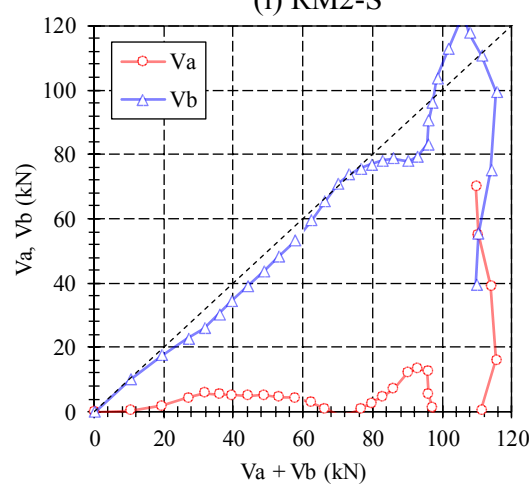

(1) RM2-T

Fig. 15 Contributions in arch and beam mechanism versus applied load (in case of $5.0 \mathrm{~mm}$ of crack width).

stirrups, the compressive struts were dispersively formed in the shear spans owing to vertical cracks in the case of $\mathrm{N}-\mathrm{S}$ and M2-S [Figs. 16(a) and (c)]. By contrast, in the case of M1-S, the compressive struts were localized, as the formations of struts were prevented at the positions of the holes [Fig. 16(b)]. It was considered that this local- ization of compressive struts was the reason why a predominance of $V_{a}$ occurred [Fig. 15(b)]. For beams with horizontal artificial cracks without stirrups, the widths of the compressive struts were relatively wide, and the widest compressive strut was formed in the case of M2-T [Fig. 16(f)]. In the case of N-T, M1-T, and M2-T, local- 


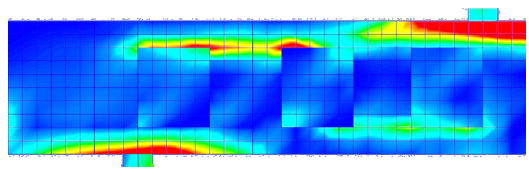

(a) $\mathrm{N}-\mathrm{S}$

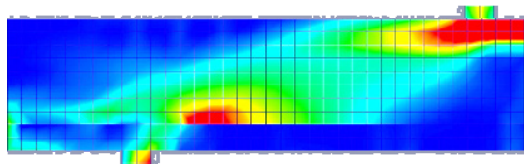

(d) N-T

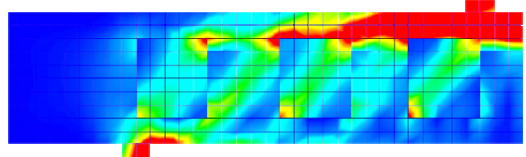

(g) RN-S

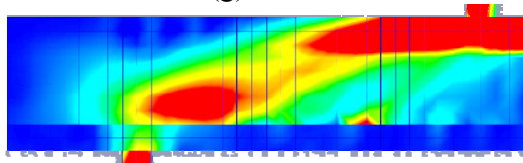

(j) RN-T

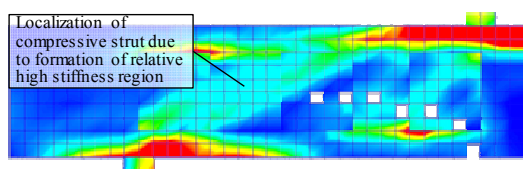

(b) M1-S

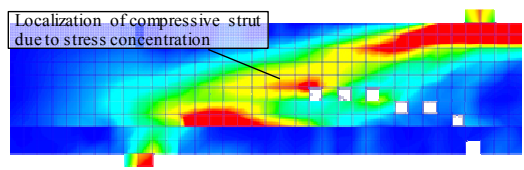

(e) M1-T

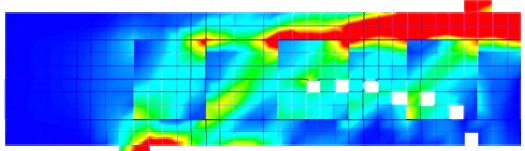

(h) RM1-S

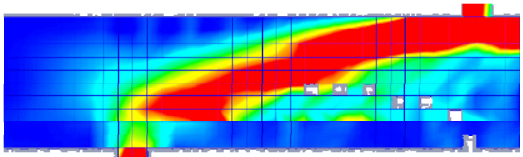

(k) RM1-T

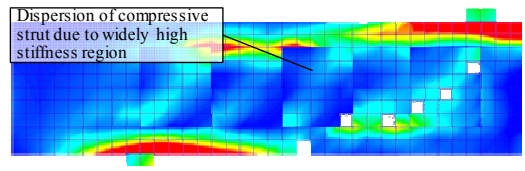

(c) M2-S

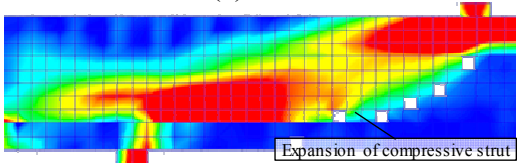

(f) M2-T

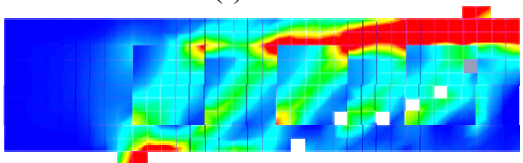

(i) RM2-S

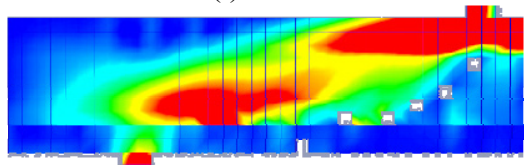

(l) RM2-T $-15=0$ (MPa)

Fig. 16 Minimum principal stress distribution map at failure (in case of $5.0 \mathrm{~mm}$ of crack width).

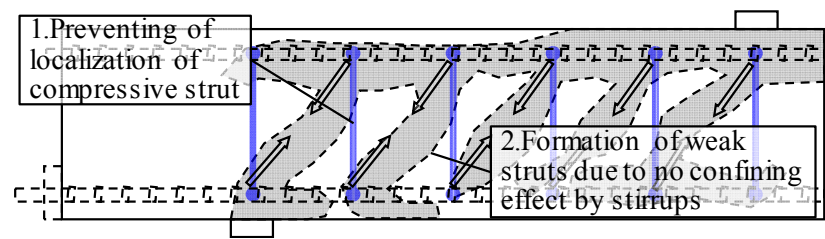

(a) N-S, M2-S

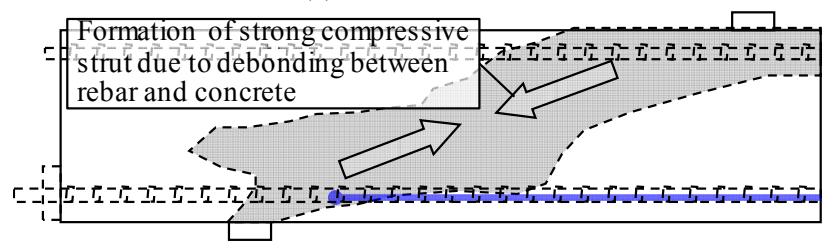

(c)N-T, M1-T

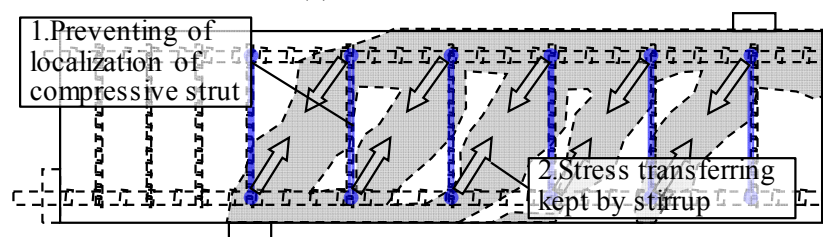

(e) RN-S, RM1-S, RM2-S

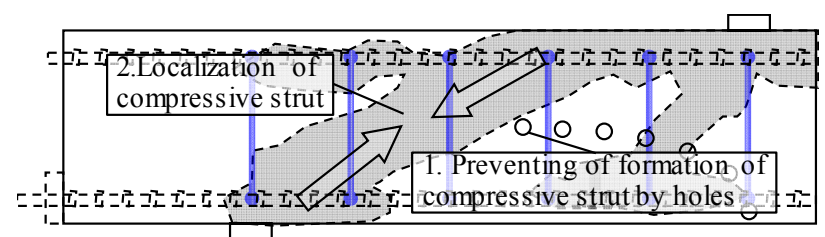

(b) M1-S

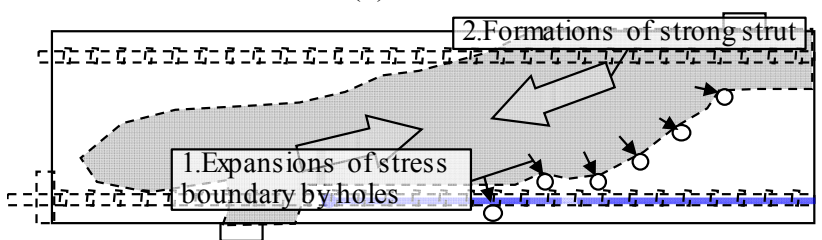

(d) M2-T

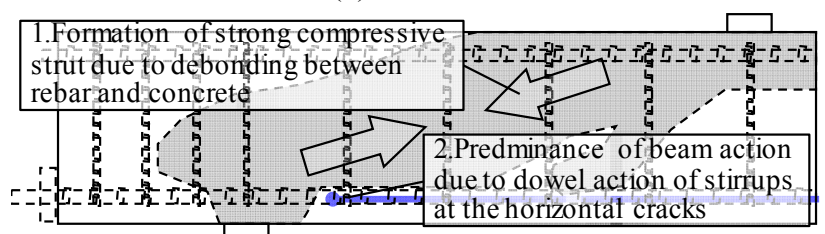

(f) RN-T, RM1-T, RM2-S

Fig. 17 Conceptual figures of categorized load carrying mechanisms.

izations of the compressive struts occurred owing to losses in the bonding forces between the concrete and tensile rebars. In particular, for M2-T, it can be considered that the holes contributed to expanding the widths of the compressive strut owing to stress concentrations. This phenomenon should be the reason why the magnitude of $V_{a}$ was larger than that for N-T and M1-T. By contrast, the stress distributions did not change significantly for beams with stirrups. This phenomenon can be attributed to the confinement effect of the stirrups, as mentioned above.

Conceptual figures of the categorized load carrying mechanisms based on the principal stress distributions are shown in Fig. 17. The load carrying mechanism can be categorized into one of six types, as shown in the figure. It can be deduced that increases in $V_{a}$ occurred by localization of the compressive strut in the case of M1-S [Fig. 17(b)] and expansion of the compressive strut in the case of M2-T [Fig. 17(d)], and that the characteristics of the compressive struts did not change in the case of RN-S, RM1-S, and RM2-S and in the case of RN-T, RM1-T, and RM2-S.

Hence, it was confirmed that the effects of interactions between artificial cracks and multiple holes on the load carrying mechanisms were characterized by the formation properties of the compressive struts based on the minimum principal stress distributions. 


\section{Conclusions}

Nonlinear FE analyses based on experimental results were conducted to obtain fundamental knowledge of the interactions between corrosion cracks along rebars and multiple holes contributing to an increase in the shear capacities of RC beams. The corrosion cracks were modeled as artificial cracks in the analyses, and the crack positions, equivalent crack widths, and hole positions were the analytical parameters. The major results in this study were as follows:

(1) For beams with holes arranged from near the loading points toward positions of tensile rebars at the midshear span with no stirrups, when the beams had a horizontal crack, the strengths increased to the flexural capacities. However, when the beams had vertical cracks, the strengths decreased to $80 \%$ for beams without holes.

(2) For beams with holes arranged from the bottom side of the loading points toward the mid-height with no stirrups, the strength increased to between $110 \%$ and $160 \%$ compared with beams without holes regardless of the crack positions.

(3) The shear behaviors of the beams did not change when the equivalent crack width exceeded $0.3 \mathrm{~mm}$ for each case. The change in the behaviors of beams with stirrups was negligibly small regardless of the hole positions owing to the confinement effects of the stirrups.

(4) When the contributions of arch mechanisms that governed increase in the strengths were observed for beams without stirrups, the minimum principal stresses were distributed widely or locally between supporting points and loading points owing to the stress concentrations of the holes. By contrast, changes in the distributions were not observed for beams with stirrups owing to the confinement effect.

(5) The interactions between artificial cracks and multiple holes in load carrying mechanisms were characterized by the formation properties of compressive struts based on minimum principal stress distributions. For beams with holes arranged from near the loading points toward the positions of tensile rebars at the midshear span with no stirrups, when the beams had a horizontal crack, strong struts were formed by widely distributed minimum principal stresses. However, when the beams had vertical cracks, weak struts were formed by the stresses whose distributions were prevented by the cracks. Meanwhile, for beams with holes arranged from the bottom side of the loading points toward the mid-height with no stirrups, even if the beams had vertical cracks, strong struts were formed by localized minimum principal stresses owing to the stress concentrations of the holes.

Experimental verification of the results above is required in future research studies.

\section{References}

Aoyagi, Y. and Yamada, K., (1983). "Strength and deformation characteristics of reinforced concrete shell elements subjected to in-plane forces." Proc. of JSCE, 331, 167-180.

fib, (2010). "fib model code for concrete structures 2010." Lausanne, Switzerland: Fédération Internationale du Béton.

Ith, V., Matsumoto, K. and Niwa, J., (2014). "Mechanical characteristics of RC beams with corroded stirrups or main reinforcements." Proceedings of the Japan Concrete Institute, 36(1), 1288-1293.

Khan, M. S., Prasad, J. and Abbas, H., (2010). "Shear strength of RC beams subjected to cyclic thermal loading." Construction and Building Materials, 24(10), 1869-1877.

Kobayashi, K. and Sasaki, N., (2014). "Fundamental study to control shear failure of RC members with high tensile strength region." Proceedings of the Japan Concrete Institute, 36(2), 7-12. (in Japanese)

Maekawa, K., Pimanmas, A. and Okamura, H., (2003). "Nonlinear mechanics of reinforced concrete." London: Spon Press.

Nakamura, H., Iwamoto, T., Fu, L., Yamamoto, Y., Miura, T. and Gedik, H. Y., (2018). "Shear resistance mechanism evaluation of RC beams based on arch and beam actions." Journal of Advanced Concrete Technology, 16(11), 563-576.

Nakarai, K., Morito, S., Ehara, M. and Matsushita, S., (2016). "Shear strength of reinforced concrete beams: concrete volumetric change effects." Journal of Advanced Concrete Technology, 14(5), 229-244.

Okamura, H. and Higai, T., (1980). "Proposed design equation for shear strength of reinforced concrete beams without web reinforcement." Proc. of JSCE, 300, 131-141.

Ou, Y. C. and Chen, H. H., (2014). "Cyclic behavior of reinforced concrete beams with corroded transverse steel reinforcement." Journal of Structural Engineering, 145(8), 1-10.

Park, R. and Paulay, T., (1975). "Reinforced concrete structures." New York: John Wiley \& Sons.

Pimanmas, A. and Maekawa, K., (2001). "Control of crack localization and formation of failure path in $\mathrm{RC}$ members containing artificial crack device." Journal of Materials, Concrete Structures and Pavements, JSCE, 52(683), 173-186.

Sasano, H., Maruyama, I., Nakamura, A. and Yamamoto, Y., (2018). "Impact of drying on structural performance of reinforced concrete shear walls." Journal of Advanced Concrete Technology, 16(5), 210-232.

Ullah, R., Yokota, H., Hashimoto, K. and Goto, S., (2016). "Load carrying capacity of RC beams with locally corroded shear reinforcement." Journal of Asian Concrete Federation, 2(1), 46-55.

Xia, J., Jin, W. L. and Li, L. Y., (2011). "Shear performance of concrete beams with corroded stirrups in chloride environment." Corrosion Science, 53, 
1794-1805.

Yamada, Y., (2018a). "Fatigue load carrying mechanism of reinforced concrete beams with corrosion cracks along tensile rebar." Thesis (PhD). Tokyo Institute of Technology.

Yamada, Y., (2018b). "Effect of drilling hole positions on shear load carrying mechanism of RC beams due to change in stress fields." Proceedings of the Japan Concrete Institute, 40(2), 595-600. (in Japanese)

Yamada, Y., (2019). "Effect of crack path on shear load carrying mechanism of RC beams." In: Proceedings of the 8th Civil Engineering Conference in the Asian Region CECAR 8, Tokyo 16-18 April 2019. Tokyo: The Asian Civil Engineering Coordinating Council,
2873353, 1-13

Yamada, Y., Chijiwa, N. and Iwanami, M., (2016). "Shear fatigue load carrying mechanism of reinforced concrete beam with artificial cracks along tensile rebar.” In: K. Maekawa, A. Kasuga and J. Yamazaki, Eds. Proceedings of the 11th fib International PhD Symposium in Civil Engineering, Tokyo 29-31 August 2016. Netherlands: A. A. Balkema Publishers, 111-117.

Yamada, Y., Chijiwa, N. and Iwanami, M., (2018). "Effect of stirrups on shear fatigue load carrying mechanism of RC beams with rebar corrosion cracks." Journal of JSCE, Ser. E2 (Materials and Concrete Structures), 74(3), 176-191. (in Japanese) 